\title{
Laparoscopic Needle-Assisted Repair for Pediatric Inguinal Hernia
}

\author{
Mhmmad Nassif $^{1}$ (D) $\cdot$ Ahmad Saad $^{2} \cdot$ Mohammad Nasser $^{1}$
}

Received: 5 February 2020 / Accepted: 24 April 2020

(C) The Author(s) 2020

\begin{abstract}
Laparoscopic needle-assisted repair (LNAR) has recently emerged as a safe and effective alternative procedure to manage pediatric inguinal hernia. However, the literature does not address the case of the efficacy of performing the LNAR by trainees or surgeons with no wide experience in laparoscopy. Therefore, the focus of the present study is to present the results of conducting such a procedure by professionals who do not possess such an experience. In a 12-month period, we performed 18 laparoscopic needle-assisted repairs for indirect pediatric inguinal hernias by one surgeon. We have collected and analyzed data concerning operating time, postoperative course and complications, need for analgesia, recurrence, and cosmetic results. No incidents during surgery have been recorded. Fifteen patients underwent laparoscopic surgery. Two contralateral hernias were intraoperatively diagnosed. Mean time of surgery, mean hospital stay, operating time, the need for postoperative analgesia, and recurrence were close to other studies performed by experts. All procedures were completed laparoscopically. The LNAR is a simple, effective, and safe procedure even when performed by trainees or surgeons without large previous experience in laparoscopy.
\end{abstract}

Keywords LNAR $\cdot$ Needle-assisted $\cdot$ Pediatric $\cdot$ Hernia

\section{Introduction}

Congenital inguinal hernia is one of the most frequently surgical problems in infants and children. Open herniotomy is the standard method of treatment, based on which other modalities of repair are evaluated. However, in the recent years, laparoscopic hernia repair has been routinely performed at many facilities, as its efficacy and safety are well documented $[1,2]$. Several techniques have been used to intracorporeally or extracorporeally suture the internal inguinal ring (IIR). Laparoscopic needle-assisted repair (LNAR) for pediatric inguinal hernia has been confirmed as a feasible, effective, and safe procedure; however, in most studies conducted on the subject, the

Mhmmad Nassif

mhmmadnassif@gmail.com

Ahmad Saad

Drsaadahmad@gmail.com

Mohammad Nasser

mohammadnasser554@gmail.com

1 Department of Pediatric Surgery, Tishreen University Hospital, Latakia, Syria

2 Department of General Surgery, Tishreen University Hospital, Latakia, Syria intervention is performed by experts [2]. This may explain why laparoscopic surgery in children has largely remained limited owing to the fact that, outside Europe and North America, the majority of pediatric surgeons have not received relative training on performing such a surgical intervention. A questionnaire conducted by the EUPSA-BAPS in 2012 which included views from 187 pediatric surgeons revealed that approximately $79 \%$ of the responders routinely perform laparoscopy for other conditions, but of these, only $22 \%$ of the responders routinely perform laparoscopic inguinal hernia repair [3]. The aim of this study is to evaluate the feasibility, efficacy, and safety of the LNAR procedure when it is performed by surgeons with no large previous experiences in laparoscopy, especially in light of LNAR being a rather simple approach.

\section{Methods}

This prospective study was conducted at Tishreen University Hospital in Latakia, Syria, between March 2018 and April 2019. Fifteen children with 18 hernia (3 bilateral) underwent LNAR surgery by one surgeon, the first of its kind at this hospital and in the country overall. Operative time, intraand postoperative complications, postoperative pain, and cosmetic aspects were recorded. Patients were followed for an average of 12 months to evaluate the outcomes. Procedures 


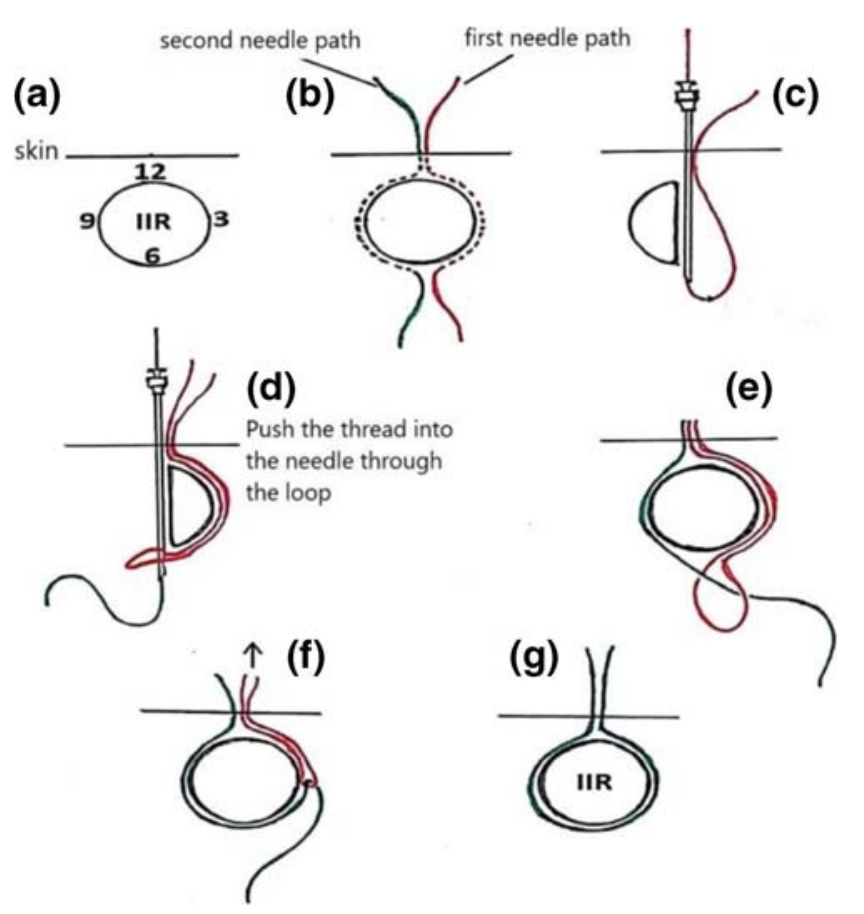

Fig. 1 LNAR technique

were performed under general anesthesia. A supraumbilical 5$\mathrm{mm}$ port for camera was made. By using a $0^{\circ}$ scope, IIR was identified in order to locate the patent processus vanginalis and the contralateral occult hernia. A small 3-mm stab incision was made in the inguinal region.

An 18G needle with folded 2-0 prolene was inserted laterally to the IIR (Fig. 1), which penetrated the peritoneum at the 6 o'clock position, forming a loop lateral to the ring (Fig. 2); then, the needle was pulled out and re-inserted medial to the IIR until it penetrated the peritoneum at the same previous position. With the needle inside the loop (Fig. 3), the other end of the suture was needle-thrusted into the prolene loop before pulling the needle out. The loop was later drawn out along the medially inserted prolene.

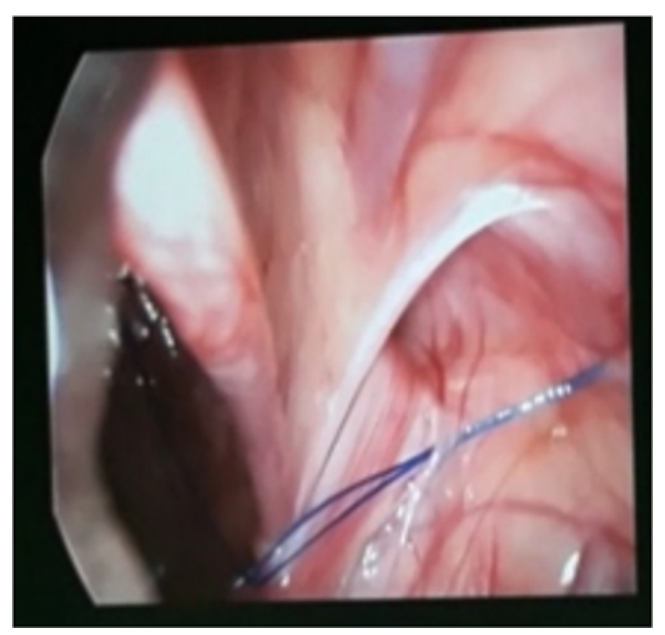

Fig. 2 First needle insertion, the peritoneum penetration at the 6 o'clock position, forming a loop lateral to the ring

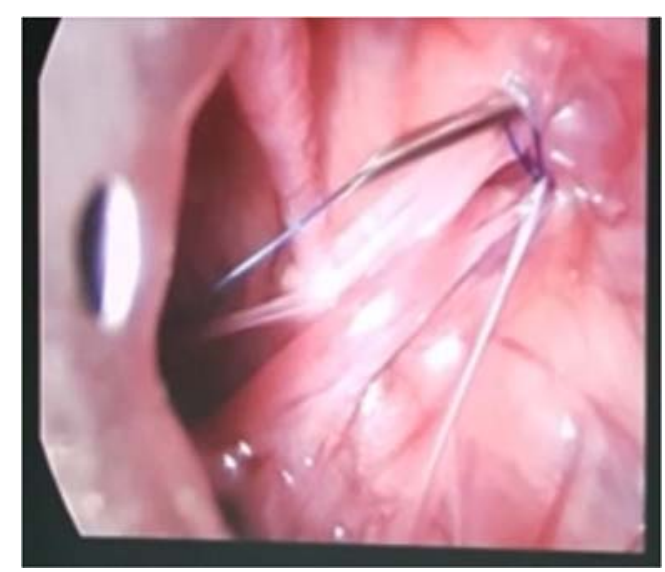

Fig. 3 Second needle insertion, needle inside the loop

The ring was encircled in an extraperitoneal plane, and the knot was extracorporeally tied and buried beneath the skin. No graspers or other intraperitoneal instruments were used. All procedures were performed under direct supervision without direct intervention.

\section{Results}

Fifteen patients (10 male and 5 female) underwent laparoscopic surgery. Patient's median age at operation was 4.4 years (20 days-12 years). Nine hernias were on the right side, 3 on the left and 3 bilateral ( 2 of them intraoperatively diagnosed). Mean time of surgery was 22.6 (14-35) min for unilateral hernias and 27.3 (12-55) min for bilateral hernias. All patients were postoperatively followed up for an average of 12 months (717 months). All procedures were completed laparoscopically without the need to be converted to open approach (Table 1).

No significant intra-operative complications occurred. Postoperative complications were grouped into major and minor complications. The overall rate of recurrence was $0 \%$ for the total number of repairs. No other major complications were identified, and there were no instances of testicular atrophy or edema. There were neither any injuries in the vas deferens nor any episodes of bleeding or mortalities.

Table 1 Results

\begin{tabular}{ll}
\hline Parametersa & Observations \\
\hline No. of cases & 15 \\
No. of repairs & 18 \\
Mean age & 4.4 years $(20$ days -12 years $)$ \\
Sex & $\mathrm{M}=10, \mathrm{~F}=5$ \\
Side of hernia & $\mathrm{RT}=9(60 \%), \mathrm{LT}=3$ \\
& $(20 \%), \mathrm{B} / \mathrm{L}=3(20 \%)$ \\
Mean follow-up & 12 months $(7-17$ months $)$ \\
Occult PPV & $2 / 14(14.2 \%)$ \\
Mean operative time & 22.6 min $(14-35$ min $)$, \\
& $\mathrm{B} / \mathrm{L}-27.3$ min $(12-55 \mathrm{~min})$ \\
Recurrent hernias & 0 \\
No. of cases converted to open surgery & 0 \\
\hline
\end{tabular}


Table 2 Comparison with other studies

\begin{tabular}{lcllllll}
\hline Author & Year & $\begin{array}{l}\text { Published } \\
\text { type of study }\end{array}$ & Pts/repairs & Type of repair & $\begin{array}{l}\text { Median operative } \\
\text { time (uni/bilat) }\end{array}$ & Grasper & Follow-up \\
\hline Yukihiro Tatekawa & 2011 & Prospective & $13 / 18$ & LPEC & $25 / 49$ & 1 & $\begin{array}{l}6.07 \text { months } \\
(2-12 \text { months })\end{array}$ \\
McClain et al. & 2014 & Prospective & $495 / 710$ & LNAR & $20 / 26$ & 1 & $\begin{array}{l}10.7 \text { months } \\
(0.3-38.4 \text { months })\end{array}$ \\
This study & 2018 & Prospective & $15 / 18$ & LNAR & $22 / 27$ & 0 & $\begin{array}{l}0.56 \%(4 / 710) \\
12.07 \text { months } \\
(7-17 \text { months })\end{array}$ \\
\hline
\end{tabular}

Results were close to other studies without significant differences and best operative time in comparison with another extracorporeal method - LPEC

No minor complications, including postoperative hydrocele, suture granuloma, or wound infections, were noted. In just one case, there was discomfort of the palpable knot under the skin, which spontaneously disappeared after 2 months. All scars were invisible. Six patients needed an additional dose of paracetamol to manage pain after discharge. Two patients had umbilical hernia simultaneously repaired.

\section{Discussion}

In our institution, there is one operating room for laparoscopy in the Department of General Surgery. Cholecystectomy, colectomy, and gastric bypass are traditionally performed, using instruments unsuitable for pediatric laparoscopy. However, we still used this operating room for the purpose of conducting the present study: the procedure was performed by a pediatric surgeon with no prior laparoscopic experience using a 5 -mm camera trocar by way of testing how doable LNAR was at the hands of trainees. Several large prospective series have been published documenting the safety and efficacy of the LNAR technique in children. A review from a single pediatric surgeon involved 495 patients who underwent 710 laparoscopic inguinal hernia repairs during the 50-month study period. Operative time (mean (range)) was 20.5 (8-57) min for single-sided repair and 26.4 (12-51) min for bilateral repair [4]. These results are comparable with what this study has found: mean surgery time was $22.6(14-35)$ min for unilateral hernias and 27.3 (12-55) min for bilateral hernias. The recurrence rate of $0.56 \%$ reported by the aforementioned study was similarly close to the $0 \%$ rate in the present study. Wound infection, recurrence and testicular atrophy, and cosmetic results were additionally similar. Moreover, laparoscopic inspection of the contralateral internal ring has been proven to be an effective technique to avoid unnecessary open exploration in patients with elevated risk of contra lateral patent processus unidentified by clinical examination. Two contralateral were detected and repaired. In comparison with another extracorporeal method-laparoscopic percutaneous extracorporeal closure (LPEC) [5] - the results of our study in relation to operative time were almost identical ( $25 \mathrm{~min}$ for unilateral; 49 min for bilateral) (Table 2).

\section{Conclusion}

The LNAR is a simple, effective, and safe procedure even when performed by trainees or surgeons without any previous experience in laparoscopy. It thus may be performed as a procedure for laparoscopy training.

\section{Compliance with Ethical Standards}

Conflict of Interest The authors declare that they have no conflict of interest.

Informed Consent Informed consent was obtained from all individual participants included in the study.

Open Access This article is licensed under a Creative Commons Attribution 4.0 International License, which permits use, sharing, adaptation, distribution and reproduction in any medium or format, as long as you give appropriate credit to the original author(s) and the source, provide a link to the Creative Commons licence, and indicate if changes were made. The images or other third party material in this article are included in the article's Creative Commons licence, unless indicated otherwise in a credit line to the material. If material is not included in the article's Creative Commons licence and your intended use is not permitted by statutory regulation or exceeds the permitted use, you will need to obtain permission directly from the copyright holder. To view a copy of this licence, visit http://creativecommons.org/licenses/by/4.0/.

\section{References}

1. Shalaby R, Ismail M, Durham A et al (2010) Laparoscopic hernia repair in infancy and childhood: evaluation of 2 different techniques. J Pediatr Surg 45(11):2210-2216

2. Schier F (2006) Laparoscopic inguinal hernia repair-a prospective personal series of 542 children. J Pediatr Surg 41:1081-1084

3. Zani A, Eaton S, Hoellwarth M, Puri P, Tover J, Fasching G et al (2013) Management of pediatric inguinal hernias in the era of laparoscopy: results of an international survey. Eur J Pediatr Surg 24:9-13

4. McClain L, Streck C, Lesher A, Cina R, Hebra A (2015) Laparoscopic needle-assisted inguinal hernia repair in 495 children. Surg Endosc 29(4):781-786

5. Tatekawa Y (2012) Laparoscopic extracorporeal ligation of hernia defects using an epidural needle and preperitoneal hydrodissection. J Endourol 26(5):474-477

Publisher's Note Springer Nature remains neutral with regard to jurisdictional claims in published maps and institutional affiliations. 